Article

\title{
Porous $\mathrm{Al}_{2} \mathrm{O}_{3}-\mathrm{CNT}$ Nanocomposite Membrane Produced by Spark Plasma Sintering with Tailored Microstructure and Properties for Water Treatment
}

\author{
Mohamed Abdrabou Hussein ${ }^{1}\left(\mathbb{D}\right.$, Hafiz Khurram Shahzad ${ }^{2}\left(\mathbb{D}\right.$, Faheemuddin Patel $^{2}\left({ }^{\circ}\right.$, \\ Muataz Ali Atieh ${ }^{3}$, Nasser Al-Aqeeli ${ }^{2}$, Turki Nabieh Baroud ${ }^{2}$ (D) and Tahar Laoui ${ }^{2, *(D)}$ \\ 1 Center of Research Excellence in Corrosion, King Fahd University of Petroleum \& Minerals, \\ Dhahran 31261, Saudi Arabia; mahussein@kfupm.edu.sa \\ 2 Department of Mechanical Engineering, King Fahd University of Petroleum \& Minerals, \\ Dhahran 31261, Saudi Arabia; mirzakhurram66@gmail.com (H.K.S.); faheemmp@kfupm.edu.sa (F.P.); \\ naqeeli@kfupm.edu.sa (N.A.-A.); turkibaroud@kfupm.edu.sa (T.N.B.) \\ 3 Department of Chemical Engineering, King Fahd University of Petroleum \& Minerals, \\ Dhahran 31261, Saudi Arabia; dr.muatazali@gmail.com \\ * Correspondence: tlaoui@kfupm.edu.sa
}

Received: 9 February 2020; Accepted: 3 March 2020; Published: 28 April 2020

\begin{abstract}
Ceramic-based nanocomposite membranes are gaining great attention in various applications, such as water treatment; gas separation; oil and gas, amid their superior fouling resistance and remarkable chemical/thermal stability. Here, we report for the first time the use of spark plasma sintering (SPS) process to fabricate a porous alumina-carbon nanotubes $\left(\mathrm{Al}_{2} \mathrm{O}_{3}-\mathrm{CNT}\right)$ nanocomposite membrane for water treatment. The challenge is this work is to achieve a balance between the amount of porosity, desired for a high water flux, and the membrane strength level, required to resist the applied pressure during a water flow experiment. The effect of SPS process parameters (pressure, temperature, heating rate, and holding time) on the microstructure and properties of the developed membrane was investigated and correlated. A powder mixture composed of $\mathrm{Al}_{2} \mathrm{O}_{3}$ and $5 \mathrm{wt} \% \mathrm{CNT}$ was prepared with the addition of starch as a pore former and gum Arabic and sodium dodecyl sulfate as dispersants. The powder mixture was then sintered using SPS to produce a solid but porous nanocomposite membrane. The structure and microstructure of the developed membrane were characterized using X-ray diffraction and field emission scanning electron microscopy. The performance of the membrane was assessed in terms of porosity, permeability, and mechanical properties. Moreover, the adsorption capability of the membrane was performed by evaluating its removal efficacy for cadmium (II) from water. The microstructural analysis revealed that CNT were distributed within the alumina matrix and located mainly along the grain boundaries. The permeability and strength were highly influenced by the sintering pressure and temperature, respectively. The results indicated that the membrane sintered at a pressure of $10 \mathrm{MPa}$, temperature of $1100^{\circ} \mathrm{C}$, holding time of $5 \mathrm{~min}$, and heating rate of $200^{\circ} \mathrm{C} / \mathrm{min}$ exhibited the best combination of permeability and strength. This developed membrane showed a significant removal efficiency of $97 \%$ for cadmium (II) in an aqueous solution.
\end{abstract}

Keywords: membrane; carbon nanotubes; alumina; ceramic nanocomposite; spark plasma sintering; water treatment

\section{Introduction}

Water treatment has become an essential necessity due to water shortages, and sometimes water crises, in many regions around the world. This has led to the search for and development 
of cost-effective technologies to address the issues related to water pollution, water reuse, and preservation of water resources [1]. Water treatment processes aim to remove undesirable constituents from water. Among the many prevailing water treatment processes, membrane filtration is considered promising and, therefore, widely accepted [2,3]. Water treatment using membrane-based separation process plays a significant role in the water treatment sector, due to its relative ease of operation, and often without chemical additives [4,5]. Ideally, membranes must have high efficiency, high stability, and low energy requirements. They should also provide a physical barrier for the "constituents of interest" based on their size. Though various categories of materials (i.e., organic and inorganic) have been utilized for membranes' development, ceramic membranes have attracted more attention than polymeric counterparts because of their higher fouling resistance and chemical stability [5]. Although, the polymeric membrane is usually used for water treatment, due to ease of pore-forming and a relatively low cost, however, several challenges are encountered such as low resistance to fouling and low mechanical strength [6,7]. The inorganic membrane presents several advantageous properties for water treatment applications including higher resistance to chemical cleaning and wear, and better mechanical/thermal stability, thus yielding a longer service life [7].

Hydrophilic metal oxide nanoparticles, such as $\mathrm{Al}_{2} \mathrm{O}_{3}$ [8], $\mathrm{SiO}_{2}$ [9], zeolite [10], and $\mathrm{TiO}_{2}$ [11], are among the attractive membrane materials because of their high water permeability. Alumina has been reported to be a good absorbent [12]. In addition, incorporating nanomaterials into the membrane, improves its permeability, thermal stability, fouling resistance, and mechanical properties, as well as providing new functions like self-cleaning and contaminant degradation [2]. One example of such a nanomaterial additive is carbon nanotubes (CNT), which have been found to be attractive for heavy metal ions removal [13-19] and water purification applications [20-34] due to their unique properties, including enhanced permeability, contaminant rejection, disinfection, and antifouling behavior. Thus, the incorporation of CNT to the alumina membrane should improve its heavy metals absorption capacity. Multi-wall carbon nanotubes (MWCNT) exhibit better mechanical characteristics [35], and higher water permeability compared to Single-wall carbon nanotubes (SWCNT) [36]. Therefore, it is selected for the current study. Although the biocompatibility of CNT still remains debatable [37], it can potentially be improved with the use of CNT-based composites [38]. In composite materials' development, the processing route is considered crucial to attaining the final material's performance.

Various processing routes were reported for the synthesis of ceramic-based nanocomposite membranes, including conventional sintering [39,40], vibration, and pressing compaction techniques [41]. Vibration and pressing compaction methods were commonly reported for the fabrication of porous alumina and alumina-silica supports [41]. Porous alumina supports were also fabricated by conventional sintering [42]. Porous alumina that was structurally modified with CNT was synthesized by gel casting followed by high-temperature reductive sintering [43]. Porous alumina-CNT composites were also synthesized by the in-situ growth of CNTs within the porous alumina matrix via thermal pyrolysis [44].

Spark plasma sintering (SPS) is preferred over conventional sintering techniques due to its ability to apply relatively fast both pressure and temperature simultaneously which facilitate the formation of fine pores. SPS enables higher heating rate, reduced sintering time, and temperature compared to conventional sintering. Moreover, SPS yields higher strength at lower processing temperatures compared to hot pressing [45] and conventional sintering [46]. The membrane's porosity can be manipulated by controlling the SPS temperature [47]. Therefore, the SPS technique has been reported to be promising for synthesizing porous ceramics [48]. Furthermore, improvements in the performance and reliability of such porous structures via controlling pore geometry have been reported [49-53]. To our knowledge, there are no reports about the synthesis of alumina-CNT nanocomposite porous membranes using SPS technique.

In the present work, we report the use of SPS to synthesize porous alumina-CNT nanocomposite membrane and the influence of SPS process parameters on the membrane's properties, namely porosity, permeability, and mechanical strength. A nanocomposite powder consisting of alumina with $5 \mathrm{wt} \%$ CNT was prepared and consolidated into a porous membrane using SPS. The membrane's 
properties were characterized and interrelated with the SPS parameters to obtain the best combination of membrane strength and permeability. Finally, the membrane's potential to remove cadmium ions (Cd (II) or $\mathrm{Cd}^{2+}$ ) from water was evaluated.

\section{Experimental Methods}

\subsection{Raw Materials and Preparation of Nanocomposite Powder}

The nanocomposite powder mixture was prepared from a commercial $\alpha$-alumina powder of $0.3 \mu \mathrm{m}$ particle size (purity $>95 \%$ ) supplied by Buehler (Braunschweig, Germany). The purified multiwalled carbon nanotubes (MWCNT) (referred to as CNT for simplicity) with an outer diameter (OD) of 10-20 nm and a length of 10-30 $\mu \mathrm{m}$ was supplied by Times Nano (Chengdu, China). Starch (Merck, Darmstadt, Germany), was used as pore former. Polyvinyl alcohol (PVA) (Merck, Darmstadt, Germany), was used as a binder material. Gum Arabic (GA) (Scharlau, Barcelona, Spain) and sodium dodecyl sulfate (SDS) (Merck, Darmstadt, Germany), were used as dispersants.

The adopted approach to prepare alumina-CNT nanocomposite powder is illustrated in Figure 1. The first solution was prepared by adding CNT (5 wt \%) to 2 liters of distilled water containing (2.5 wt \%) GA and (2.5 wt \%) SDS. Then, the solution was hand-mixed before being subjected to ultrasonication by probe-sonicator (Sonics, Newtown, Connecticut, USA) for $2 \mathrm{~h}$. Another solution was prepared by adding a mixture of $\alpha$-alumina powder (95 wt \%) and (5 wt \%) starch to distilled water. Both solutions were then mixed and sonicated for $2 \mathrm{~h}$ before being placed on a hot plate at $80{ }^{\circ} \mathrm{C}$ under continuous stirring for water evaporation. The resulting composite powder was further dried in an oven at $70{ }^{\circ} \mathrm{C}$ overnight. The dried composite powder was hand crushed to obtain a fine composite powder. To improve the compaction of the composite powder, a binder solution was prepared by dissolving 2 wt \% PVA in distilled water and stirred at $80^{\circ} \mathrm{C}$ until a clear solution was obtained. Finally, a $10 \mathrm{wt} \%$ binder solution was added to the nanocomposite powder.

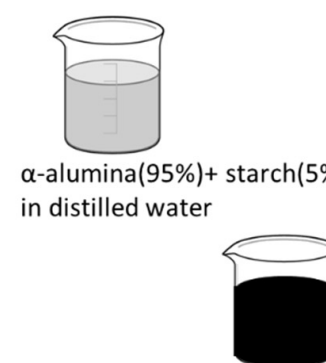

CNT(5 wt. \%) in distilled water + GA \& SDS (2.5\% each)

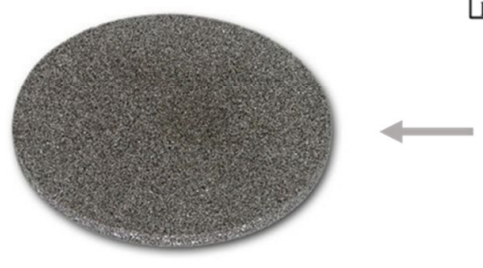

Alumina-CNT nanocomposite membrane

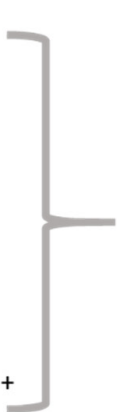
hour

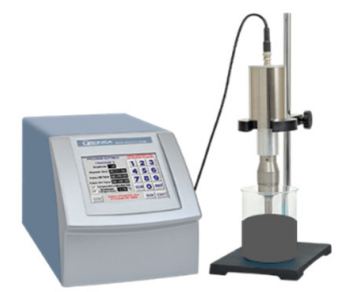

Probe sonication of all the constituents alumina+ CNT+ starch+ GA+ SDS) for 2 hours

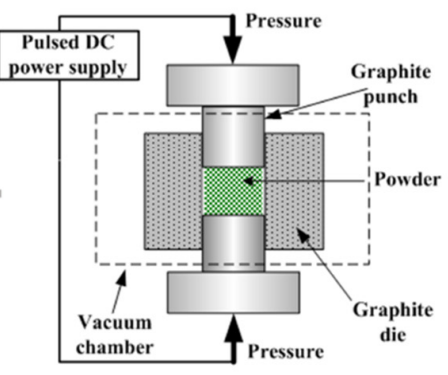

Spark Plasma Sintering (SPS)

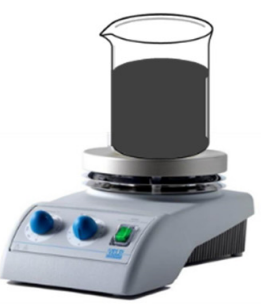

Drying the powder mixture on hotplate at $80^{\circ} \mathrm{C}$ with continuous stirring
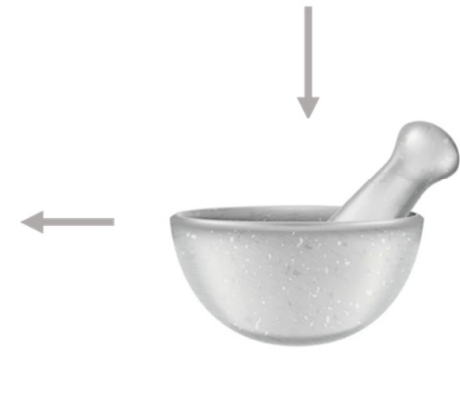

Careful hand crushing of fine powder mixture (alumina-CNT)

Figure 1. Approach and steps used for the preparation of alumina-carbon nanotubes (CNT) powder mixture and membrane. 


\subsection{Processing of Membrane Using Spark Plasma Sintering}

Porous alumina-CNT composite membrane was fabricated using SPS machine (FCT system-model HP D5, Rauenstein, Germany) and a 30-mm graphite die. A graphite sheet was first placed inside the graphite die before adding the nanocomposite powder in order to facilitate easy removal of the sample and to reduce the friction between the die walls and the powder. The experiments were conducted in vacuum under the pressures $(\mathrm{P})$ of 5,10 , or $20 \mathrm{MPa}$ at the sintering temperatures (T) of 1000, 1100, or $1200^{\circ} \mathrm{C}$, heating rates (HR) of 50,100 , or $200{ }^{\circ} \mathrm{C} / \mathrm{min}$, and the holding times (t) of $2.5,5$, or $10 \mathrm{~min}$. A parametric study was conducted to examine the influence of the SPS parameters on the membrane properties. Table 1 shows the different processing parameter sets and the assigned sample codes.

Table 1. Spark plasma sintering (SPS) processing parameters, porosity, diametrical strength, and permeability of SPS samples.

\begin{tabular}{cccccccc}
\hline \multicolumn{7}{c}{ Processing Parameters } & \multicolumn{3}{c}{ Experimental Results } \\
\hline $\begin{array}{c}\text { Sample } \\
\text { Code }\end{array}$ & $\begin{array}{c}\text { Temperature } \\
\left({ }^{\circ} \mathbf{C}\right)\end{array}$ & $\begin{array}{c}\text { Time } \\
(\mathbf{m i n})\end{array}$ & $\begin{array}{c}\text { Heating Rate } \\
\left({ }^{\circ} \mathbf{C} / \mathbf{m i n}\right)\end{array}$ & $\begin{array}{c}\text { Pressure } \\
(\mathbf{M P a})\end{array}$ & $\begin{array}{c}\text { Porosity } \\
\mathbf{( \% )}\end{array}$ & $\begin{array}{c}\text { Diametrical } \\
\text { Strength }(\mathbf{M P a})\end{array}$ & $\begin{array}{c}\text { Permeability } \\
\left(\mathbf{L} / \mathbf{m}^{\mathbf{2}} \cdot \mathbf{h r} \cdot \mathbf{b a r}\right)\end{array}$ \\
\hline SPS-1 & 1000 & 10 & 100 & 20 & 10.77 & 12.3 & 12.31 \\
SPS-2 & 1000 & 10 & 100 & 10 & 56.2 & 6.9 & 39.45 \\
SPS-3 & 1000 & 10 & 100 & 5.6 & 69.7 & 1.9 & NA \\
SPS-4 & 1000 & 10 & 50 & 10 & 33.2 & 8 & 35.34 \\
SPS-5 & 1000 & 10 & 200 & 10 & 60.7 & 4.9 & 44.58 \\
SPS-6 & 1000 & 5 & 200 & 10 & 67.5 & 4.1 & 41.32 \\
SPS-7 & 1000 & 2.5 & 200 & 10 & 69.3 & 3.4 & 45.86 \\
SPS-8 & 1100 & 5 & 200 & 10 & 64 & 9.5 & 37.89 \\
SPS-9 & 1200 & 5 & 200 & 10 & 50 & 10.4 & 20.53 \\
\hline
\end{tabular}

\subsection{Characterization of Sintered Membrane}

The structure and phase analysis of both as-received raw materials and SPS samples were characterized by X-ray diffraction (XRD) equipment (AXSD8, Bruker, Karlsruhe, Germany) with Cu-K $\alpha$ radiation at a scanning speed of 1 degree/min. Field emission scanning electron microscopy (Lyra3, Tescan, Brno, Czech Republic), was used to study the as-received raw materials and the microstructure, particle size, and pore size of the SPS samples. The porosity of the developed membrane was measured according to ASTM C373-14a after measuring the weight of dry and wet membranes. The diametrical compression test was performed using a universal testing machine (INSTRON) to investigate the strength of the developed membrane. The diametrical strength was then calculated from Equation (1) [54,55] below:

$$
\sigma=(2 \cdot f / \pi \cdot d t)
$$

where $f$ is the applied load, $d$ is the diameter, and $t$ is the thickness of the membrane.

\subsection{Measurement of Water Flux}

The water flux measurement was carried out using a flow loop module built in-house, as previously described (Figure 2), and the water flux J was determined using Equation (2) below:

$$
\mathrm{J}=V / A T
$$

where $V$ is the volume of the permeate water, $A$ is the effective area of the membrane, and $T$ is the time required for a specific amount of water to permeate.

The water flux was measured under a transmembrane pressure of 5-40 psi. The water permeability of the membranes was calculated at transmembrane pressure P of 40 psi by dividing the water flux J with the transmembrane pressure. 


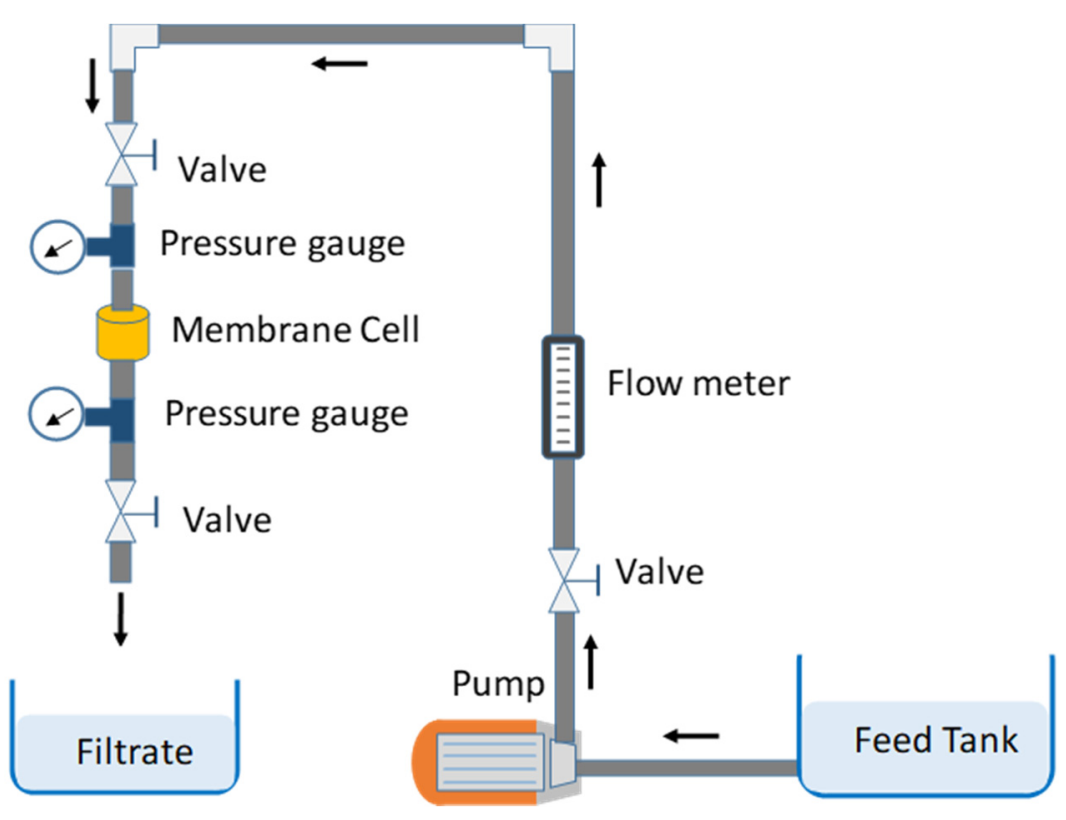

Figure 2. Schematic diagram of the flow loop module.

\subsection{Adsorption Capacity}

The cadmium (II) (Cd (II)) adsorption capacity (R \%) of the developed alumina-CNT membrane was investigated using a flow loop as depicted in Figure 2. The standard solution of cadmium (II) (1000 ppm Cd in deionized water) was prepared. The experiments were conducted in aqueous solution at room temperature and $\mathrm{pH}$ 6. The concentration of $\mathrm{Cd}$ (II) in the solution was measured by inductively coupled plasma mass spectrometry, ICP-MS (provided by Thermo Fisher Scientific, USA) before and after the experiments. Initial $\left(C_{i}\right)$ and final $\left(C_{f}\right) \mathrm{Cd}$ ions concentrations were measured, then the adsorption capacity was calculated according to Equation (3) [56]:

$$
R(\%)=\left(C_{i}-C_{f}\right) / C_{i}
$$

\section{Results and Discussion}

\subsection{Characterization of Raw Materials}

The as-received materials were examined by FE-SEM and XRD to determine their structures and microstructures. FE-SEM images showed that the as-received alumina had a uniform particle size of $0.3 \mu \mathrm{m}$ (Figure 3a), with little size variation among the particles, an important aspect for controlling the pore size. The MWCNTs had an outer diameter (OD) of 10-20 nm (Figure 3b). The XRD spectrum of the CNTs presented in Figure 4a shows two peaks corresponding to the 2-theta values of $26^{\circ}$ and $44^{\circ}$, corresponding to the hexagonal graphite lattice of the MWCNTs. Figure $4 \mathrm{~b}$ shows the XRD pattern of the as-received alumina with all the expected peaks of high-purity $\alpha$-alumina.

XRD was performed, for raw as well as all the sintered membranes, to study the influence of the SPS parameters on the structure of the membranes. Figure 4c shows an XRD pattern for a selected sample (which has exhibited the best combination of strength and permeability) sintered at $10 \mathrm{MPa}$, $1100{ }^{\circ} \mathrm{C}, 5 \mathrm{~min}$, and $200{ }^{\circ} \mathrm{C} / \mathrm{min}$. This spectrum contains only peaks related to crystalline $\alpha-\mathrm{Al}_{2} \mathrm{O}_{3}$; the same is true for the XRD spectra of all other samples in this study (not included here). The peaks related to CNT were not even partly observed, this might be due to the small quantity of added CNT, $5 \mathrm{wt} \%$, compared to the highly crystalline alumina matrix. Most importantly, no extra phases or missing peaks were noticed in any of the XRD spectra confirming that no phase changes occurred during membrane fabrication, and the final membranes consisted of the desired crystalline $\alpha-\mathrm{Al}_{2} \mathrm{O}_{3}$. 

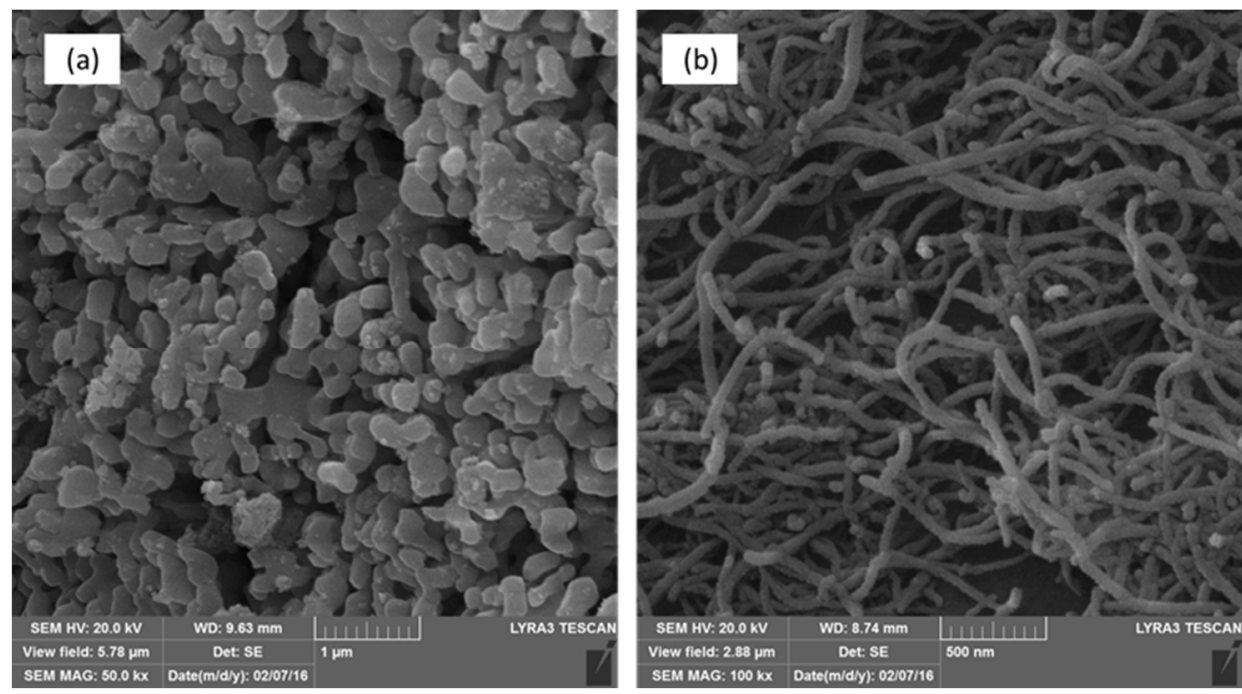

Figure 3. FE-SEM images of as-received (a) $\alpha$-alumina and (b) CNTs.

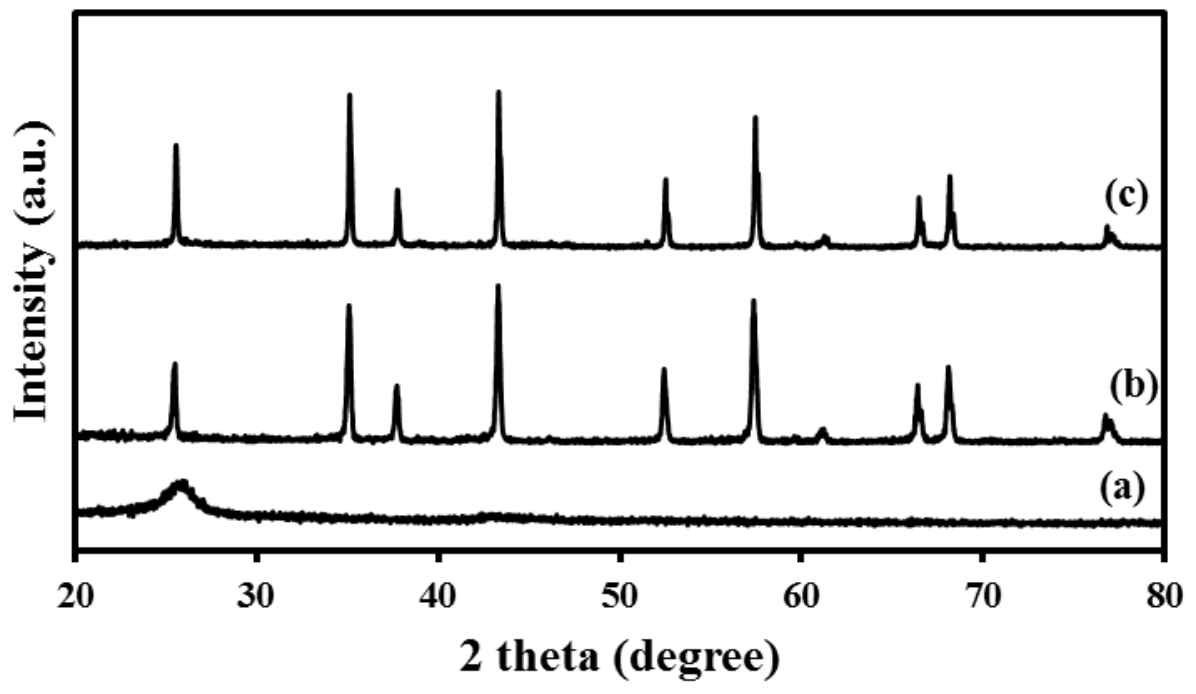

Figure 4. XRD patterns of (a) as-received CNTs, (b) as-received $\alpha$-alumina, and (c) the membrane sample sintered at $10 \mathrm{MPa}, 1100{ }^{\circ} \mathrm{C}, 5 \mathrm{~min}$, and $200^{\circ} \mathrm{C} / \mathrm{min}$.

\subsection{Microstructural Characterization of Spark Plasma Sintered Membranes}

FE-SEM was performed to investigate the microstructure and pore size of selected membrane samples. The pore size and grain growth were observed to change with increasing SPS pressure (Figure 5a,b). The membrane (Figure 5a), prepared using a sintering pressure of 5.6 MPa, showed insufficient cohesion between particles; the fine grains were very similar to those shown in the FE-SEM image of the as-received alumina (Figure 3a). Conversely, the membrane prepared using a higher pressure of $10 \mathrm{MPa}$ (Figure $5 \mathrm{~b}$ ) showed relatively larger alumina particle size and a denser microstructure due to crystal growth, with alumina particles showing neck growth along adjacent particles. This growth increased with increasing sintering pressure (Figure $5 \mathrm{a}, \mathrm{b}$ ) and temperature (Figure 5c,d).

Figure $5 \mathrm{e}, \mathrm{f}$ displays a micrograph of the fractured surface of sample SPS-4. It shows that the CNTs are well distributed within the alumina matrix and located mainly along the grain boundaries. Therefore, the nanocomposite developed in this study appears to be inter-granular [57]. Due to the simultaneous effect of pressure and temperature, SPS enables higher heating rates, shorter sintering time, and lower sintering temperature compared with conventional sintering. Hence, the utilization 
of SPS can potentially produce finer grains and smaller pores. Moreover, SPS could facilitate the production of higher-strength materials at lower temperatures compared with hot pressing and conventional sintering $[45,46]$. The effect of heating rate on the membrane porosity is shown in Figure 5e,f. At a low heating rate, the membrane demonstrates low porosity and large particles. This can be attributed to the slow sintering which in turn enables the particles to grow into larger size and subsequently decrease the amount of membrane porosity. In addition, grain shape and morphology are also affected by the low heating rate. The sintering mechanism responsible for this effect is likely to be the grain-boundary and volumetric diffusion [58,59].
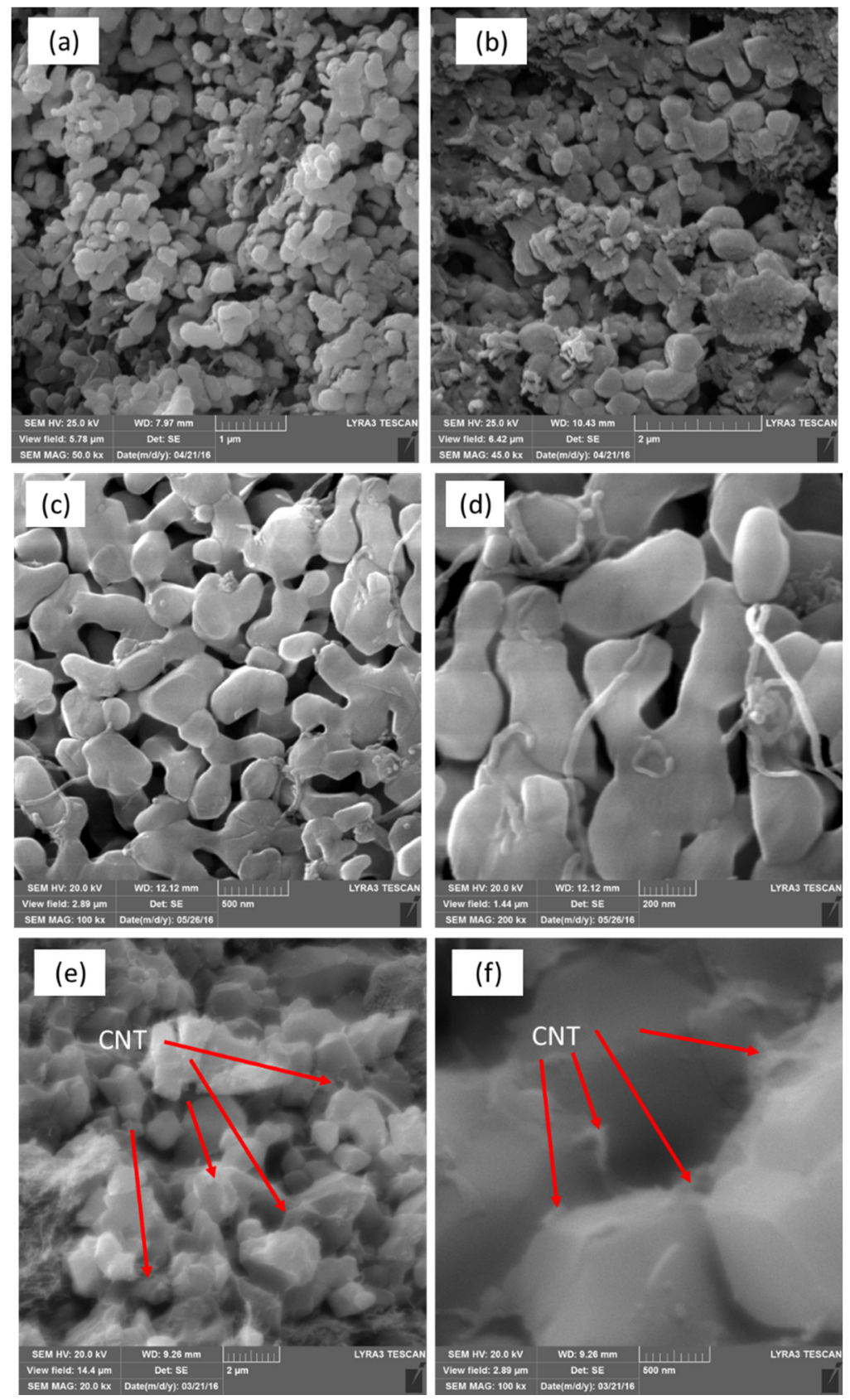

Figure 5. FE-SEM images of the membranes sintered at different SPS process parameters: (a) $5.6 \mathrm{MPa}$, $1000^{\circ} \mathrm{C}, 10 \mathrm{~min}, 100{ }^{\circ} \mathrm{C} / \mathrm{min}$, and (b) $10 \mathrm{MPa}, 1000^{\circ} \mathrm{C}, 10 \mathrm{~min}, 100^{\circ} \mathrm{C} / \mathrm{min}$; (c,d) $10 \mathrm{MPa}, 1100{ }^{\circ} \mathrm{C}, 5 \mathrm{~min}$, $200{ }^{\circ} \mathrm{C} / \mathrm{min}$; (e,f) $10 \mathrm{MPa}, 1000^{\circ} \mathrm{C}, 10 \mathrm{~min}, 50^{\circ} \mathrm{C} / \mathrm{min}$. 


\subsection{Effect of SPS Parameters on Porosity, Water Flux, and Permeability}

The permeability is the ability of the fluid to pass through the porous structure of the membrane. Both water flux and permeability depend on the porosity of the membrane. Obviously, the water flux is higher for a membrane with high porosity. The permeability depends on both water flux and transmitting pressure. The effect of SPS parameters on porosity, water flux, and permeability is presented in the following section. The porosity was measured according to the ASTM standard for ceramic materials (ASTM c373-14a) after measuring the dry and wet weights of the membrane. The water flux was measured using the flow loop as shown in Figure 2, then the permeability was calculated by dividing the water flux with the transmitting pressure.

Figure 6 displays the change in porosity and permeability of the SPS samples with varying SPS process parameters. The porosity decreased with increasing sintering pressure (Figure 6a) and temperature (Figure 6d). However, the porosity was influenced more by the sintering pressure (decreased from $69.7 \%$ at $5.5 \mathrm{MPa}$ to $10.77 \%$ at $20 \mathrm{MPa}$ ) than the sintering temperature $\left(67 \%\right.$ at $1000{ }^{\circ} \mathrm{C}$ and $50 \%$ at $1200{ }^{\circ} \mathrm{C}$ ). The elevated values of temperature and pressure contributed to the neck growth of the alumina particles and thus reduced the porosity. The observed decrease in porosity with increasing sintering pressure and temperature might be due to the sintering of adjacent particles. However, the porosity increased with the increase in heating rate (Figure 6 b) $\left(33 \%\right.$ at $50{ }^{\circ} \mathrm{C} / \mathrm{min}$ to $69 \%$ at $200^{\circ} \mathrm{C} / \mathrm{min}$ ). The holding time demonstrated a similar correlation with membrane porosity. Notably, with the increase in the holding time from $2.5 \mathrm{~min}$ to $10 \mathrm{~min}$, the porosity decreased from $69.3 \%$ to $60.7 \%$ (Figure 6c).
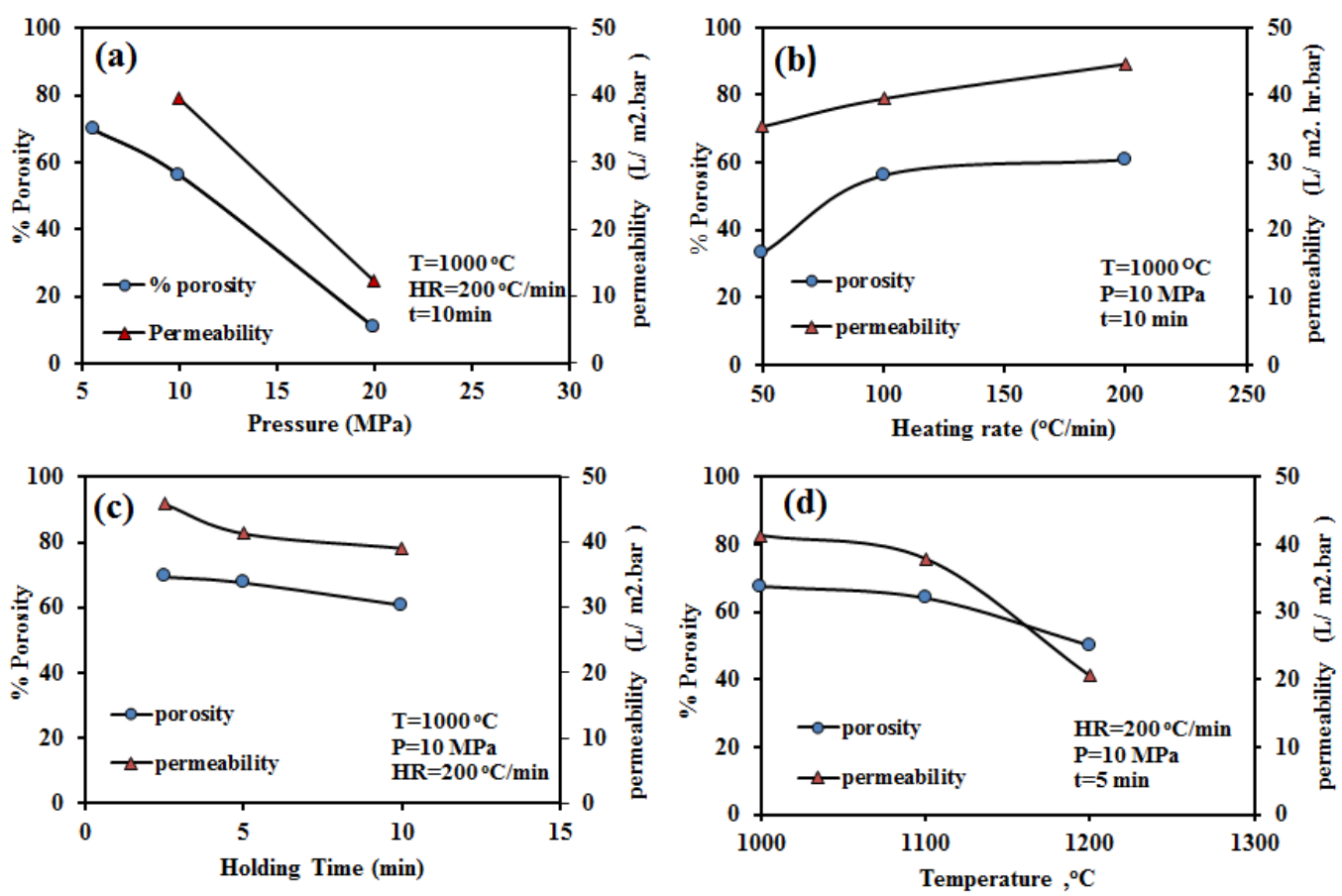

Figure 6. Variation in membrane porosity and permeability with SPS process parameters: (a) pressure, (b) heating rate, (c) holding time, and (d) temperature.

The water flux through the sintered samples was measured at a transmembrane pressure of 5-40 psi using the setup shown in Figure 2. Water flux was observed to increase with increasing transmittance pressure for all conditions (Figure 7). The water flux was found to be more influenced by the SPS pressure and temperature than by heating rate or holding time, which could be attributed to the porosity. Although the sample that was compacted at 5.6 MPa possessed the highest porosity compared to other samples, the sample broke during the water flux test. Thus, this compaction pressure yielded a membrane with low strength and consequently did not produce a sufficiently robust membrane for 
practical application. The membrane permeability for different SPS processing conditions, representing the membrane's productivity, was calculated from the water flux measurement.
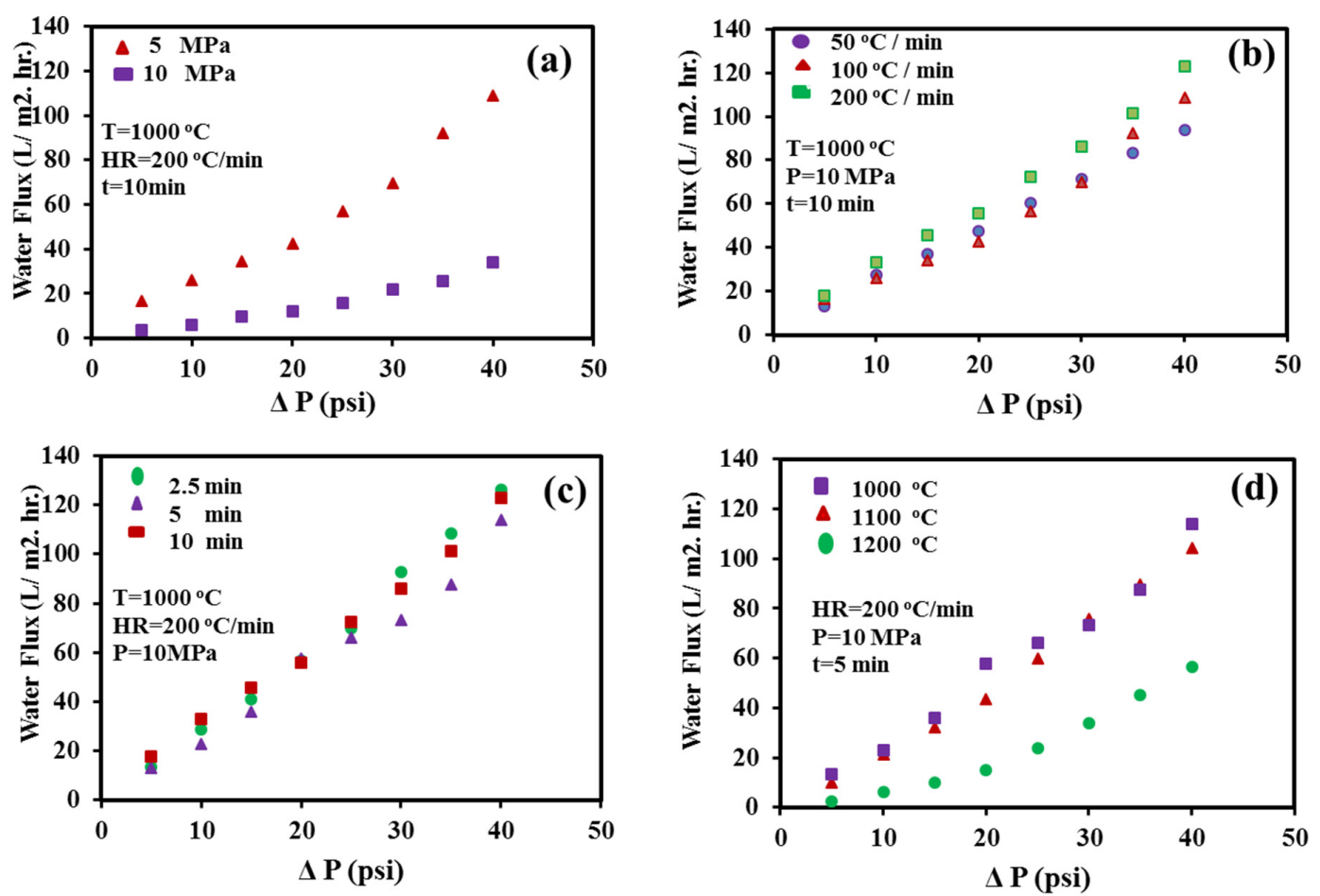

Figure 7. Variation in pure water flux under different transmittance pressures for membranes prepared with varying SPS process parameters: (a) pressure, (b) heating rate, (c) holding time, and (d) temperature.

As shown in Figure 6, the membrane permeability follows a similar trend to that of the porosity for the different processing parameters: it decreases with increasing sintering temperature (decreased from $41.58 \mathrm{~L} / \mathrm{m}^{2} \cdot \mathrm{hr} \cdot$ bar at $1000{ }^{\circ} \mathrm{C}$ to $20.53 \mathrm{~L} / \mathrm{m}^{2} \cdot \mathrm{hr} \cdot \mathrm{bar}$ at $1200{ }^{\circ} \mathrm{C}$ ). However, it increases with increasing heating rate (increased from $35.3 \mathrm{~L} / \mathrm{m}^{2} \cdot \mathrm{hr} \cdot \mathrm{bar}$ at $50{ }^{\circ} \mathrm{C} / \mathrm{min}$ to $44.5 \mathrm{~L} / \mathrm{m}^{2} \cdot \mathrm{hr} \cdot \mathrm{bar}$ at $200{ }^{\circ} \mathrm{C} / \mathrm{min}$ ). The highest permeability values of 45.86 and $44.5 \mathrm{~L} / \mathrm{m}^{2} \cdot \mathrm{hr} \cdot$ bar is obtained for the samples sintered at $\left(10 \mathrm{MPa}, 1000{ }^{\circ} \mathrm{C}, 2.5 \mathrm{~min}\right.$, and $200{ }^{\circ} \mathrm{C} / \mathrm{min}$; SPS-7), and $\left(10 \mathrm{MPa}, 1000{ }^{\circ} \mathrm{C}, 10 \mathrm{~min}\right.$, and $200{ }^{\circ} \mathrm{C} / \mathrm{min}$; SPS-5), respectively. Figure 8 depicts the permeability as a function of porosity, obtained from porous membranes processed under different process conditions. As expected, the permeability increases by increasing the percentage of porosity, in agreement with data reported in the literature [60].

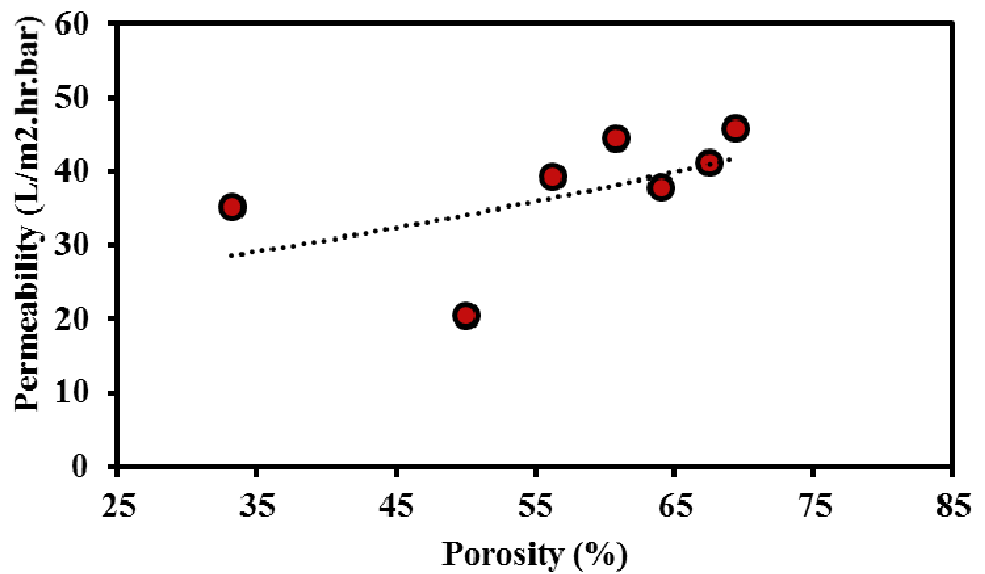

Figure 8. Variation of permeability with porosity level for different porous membranes. 


\subsection{Mechanical Properties of $\mathrm{Al}_{2} \mathrm{O}_{3}-\mathrm{CNT}$ Nanocomposite Membrane}

Diametrical compression tests were carried out to evaluate the strength of each membrane (Figure 9). In each case, the test was completed when the sample fractured into two halves (Figure 9c) because of the tensile failure [40]. Increasing the sintering temperature from $1000{ }^{\circ} \mathrm{C}$ to $1200{ }^{\circ} \mathrm{C}$ resulted in an increase in the diametrical strength of the SPS membrane from 1.9 MPa to 12.3 MPa (Table 1), a change that could be attributed to grain growth and pore shrinkage. Similar results were obtained with increasing pressure SPS-1 sintered at a pressure of $20 \mathrm{MPa}$ exhibited a strength of $12.3 \mathrm{MPa}$, whereas SPS-3 sintered at a pressure of 5.6 MPa showed a strength of $1.92 \mathrm{MPa}$ (Table 1). These findings reveal that SPS both temperature and pressure have a significant effect on the strength of the membrane. High pressure brings particles closer together during compaction, and high temperature causes them to diffuse with one another easily; this result is consistent with previous research [39]. Keeping the other parameters constant, the strength increases with increasing sintering pressure, which can be attributed to an increase in the densification of the membrane. This increase in densification reflects an increase in interface formation, which ensures effective load sharing between the matrix $\left(\mathrm{Al}_{2} \mathrm{O}_{3}\right)$ and filler (CNT), as confirmed by the FE-SEM micrograph shown in Figure 5; these results are also consistent with previous studies $[39,61]$. In contrast, the heating rate displays an antagonistic effect on strength: an increase in the heating rate from $50{ }^{\circ} \mathrm{C} / \mathrm{min}$ to $200^{\circ} \mathrm{C} / \mathrm{min}$ causes the membrane's strength to decrease from $8 \mathrm{MPa}$ to $4.9 \mathrm{MPa}$. This reduction in strength can be attributed to a higher amount of porosity, accompanied by a poor load sharing ability.
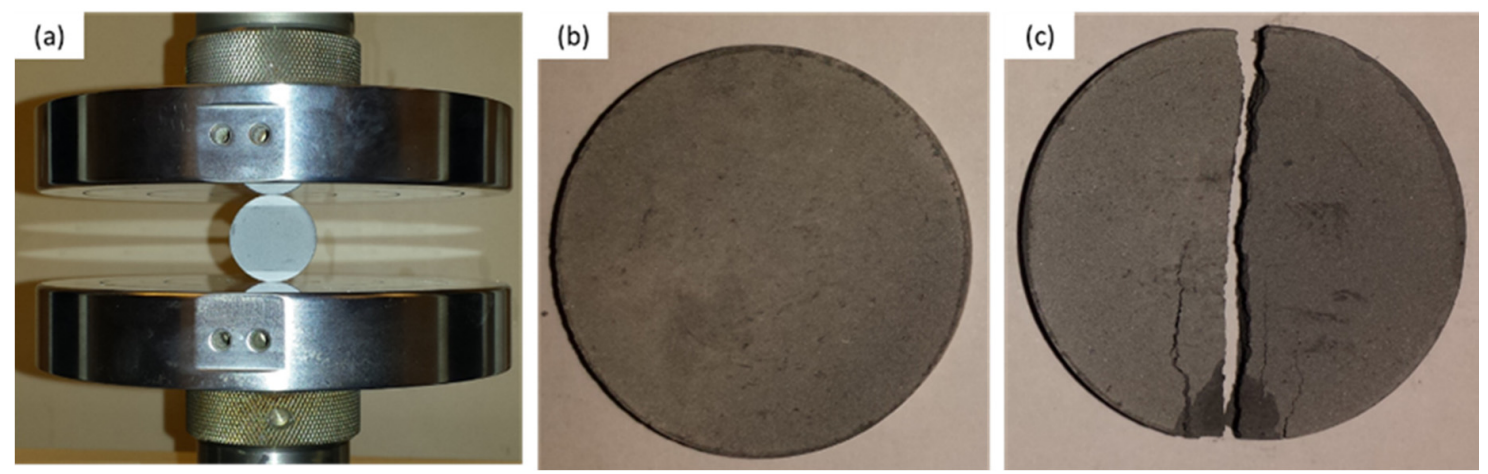

Figure 9. Diametrical compression testing: (a) configuration, (b) membrane sample before the test, and (c) fractured membrane after the test.

\subsection{Correlation between Permeability and Strength of $\mathrm{Al}_{2} \mathrm{O}_{3}-\mathrm{CNT}$ Membrane}

It is important to analyze and correlate the properties of the developed $\mathrm{Al}_{2} \mathrm{O}_{3}-\mathrm{CNT}$ nanocomposite membrane with the processing parameters to obtain the best combination in terms of permeability and strength. The permeability is related to the functionality of the membrane, while its strength plays a significant role in its reliability and service life [62]. The permeability and strength of the membranes produced under different SPS conditions (Figure 10) were analyzed to identify the best combination. Membrane SPS- 8 showed the optimal combination, followed by membranes SPS- 4 and SPS-2. The average pore size was calculated using the FE-SEM micrographs. For SPS-8, the average value of pore size was $0.14 \pm 0.04 \mu \mathrm{m}$ and ranged from $0.08 \mu \mathrm{m}$ to $0.24 \mu \mathrm{m}$. The formation of the pores is attributed to both the burning off the pore former and partial sintering $[59,63]$. 


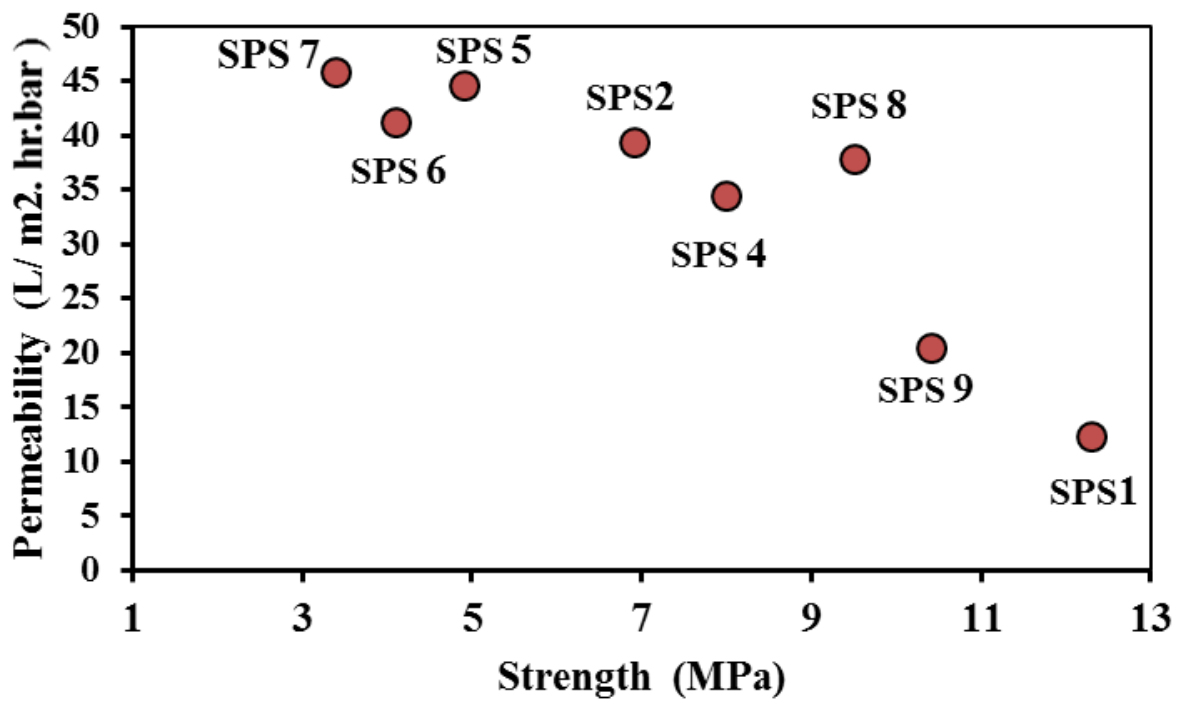

Figure 10. Permeability and strength of alumina-CNT membranes produced under different SPS process conditions.

\subsection{Adsorption Capacity of Cadmium (II) on $\mathrm{Al}_{2} \mathrm{O}_{3}-\mathrm{CNT}$ Nanocomposite Membrane}

To test the capability of the developed membrane for heavy metals removal, the adsorption capacity of cadmium (II) (or Cd (II)) from water was performed on the selected membrane (SPS-8). Adsorption capacity of Cd (II) from water was carried out using the flow loop shown in Figure 2 at $\mathrm{pH}=6$ to avoid precipitation of Cd (II) as reported in our previous work [55]. The developed membrane showed a removal efficiency of $97 \%$ for $\mathrm{Cd}$ (II), close to the values reported in the literature for other membranes $[13,64,65]$ as presented in Table 2 . Moreover, it showed a higher removal efficiency compared to either $\alpha$-alumina or alumina-CNT powder mixture tested in similar conditions [55]. The mechanism of metal ions attachment on CNT is sorption and electrostatic attraction [66], while for alumina, it is simply physical adsorption [67]. Therefore, the addition of CNT, as a filler, in the alumina matrix has improved the adsorption/removal efficiency. CNT are reported to possess a great potential for the removal of various heavy metals ions from wastewater such as $\mathrm{Cd}[68,69], \mathrm{Cr}, \mathrm{Cu}$, and $\mathrm{Ni}[69]$.

Table 2. Removal efficiency of Cd (II) by different membranes as reported in the literature.

\begin{tabular}{ccc}
\hline Membrane & Removal Efficiency (\%) & Reference \\
\hline Alumina-CNT membrane & 97 & This work \\
\hline Modified CNT & 93 & {$[13]$} \\
\hline$\alpha$-alumina & 28 & {$[55]$} \\
\hline Alumina-CNT powder mixture & 79 & {$[55]$} \\
\hline Polysulfone & $92-98$ & {$[64]$} \\
\hline Amicon regenerated cellulose & 99 & {$[65]$} \\
\hline
\end{tabular}

\section{Conclusions}

A porous alumina-carbon nanotubes $\left(\mathrm{Al}_{2} \mathrm{O}_{3}-\mathrm{CNT}\right)$ nanocomposite membrane was fabricated by spark plasma sintering (SPS). The microstructural analysis revealed that CNT were distributed within the alumina matrix and located mainly along the grain boundaries. By varying the SPS process parameters (pressure, temperature, heating rate, and holding time), the best combination of strength and membrane permeability was achieved. Overall, the SPS sintering pressure and temperature were found to be more influential factors in controlling the properties of the membrane compared to other factors such as heating rate and holding time. The porosity was influenced more by the applied 
pressure, followed by the sintering temperature. The strength, water flux, and permeability of the membrane were more influenced by the sintering temperature, followed by the applied pressure. The membrane sintered at $10 \mathrm{MPa}$ pressure, $1100{ }^{\circ} \mathrm{C}$ temperature, $5 \mathrm{~min}$ holding time, and $200{ }^{\circ} \mathrm{C} / \mathrm{min}$ heating rate revealed the best combination of permeability $\left(37.8 \mathrm{~L} / \mathrm{m}^{2} \cdot \mathrm{hr} \cdot \mathrm{bar}\right)$, and strength $(9.5 \mathrm{MP})$, along with an average pore size of $0.14 \mu \mathrm{m}$. Furthermore, this developed membrane was able to remove $97 \%$ for cadmium (II) in an aqueous solution.

The present study has allowed to delineate the impact of SPS parameters on the porous $\mathrm{Al}_{2} \mathrm{O}_{3}-\mathrm{CNT}$ membrane's properties and performance, applied here in water treatment, but could ultimately pave the way for more practical applications of ceramic membranes.

Author Contributions: Conceptualization, T.L., M.A.A., and N.A.-A.; formal analysis, M.A.H., H.K.S., T.L., M.A.A., and T.N.B.; funding acquisition, T.L., M.A.A., N.A.-A., and F.P.; investigation, H.K.S., M.A.H., and F.P.; resources, F.P.; writing — original draft, M.A.H., H.K.S., and T.L.; writing—review and editing, F.P., M.A.A., and T.N.B. All authors have read and agreed to the published version of the manuscript.

Funding: The authors would like to acknowledge the support provided by King Abdulaziz City for Science and Technology (KACST) through Science \& Technology Unit at King Fahd University of Petroleum \& Minerals (KFUPM) for funding this work through Project No: 13-ADV2184-04 as part of the National Science Technology and Innovation Plan (NSTIP).

Conflicts of Interest: The authors declare no conflicts of interest.

\section{References}

1. Yin, J.; Baolin, D. Polymer-matrix nanocomposite membranes for water treatment. J. Membr. Sci. 2015, 479, 256-275. [CrossRef]

2. Qu, X.; Alvarez, P.J.; Li, Q. Applications of nanotechnology in water and wastewater treatment. Water Res. 2013, 47, 3931-3946. [CrossRef] [PubMed]

3. Crini, G.; Lichtfouse, E. Advantages and disadvantages of techniques used for wastewater treatment. Environ. Chem. Lett. 2019, 7, 145-155. [CrossRef]

4. Elimelech, M.; Phillip, W.A. The future of seawater desalination: Energy, technology, and the environment. Science 2011, 333, 712-717. [CrossRef] [PubMed]

5. Pendergast, M.M.; Hoek, E.M.V. A review of water treatment membrane nanotechnologies. Energy Environ. Sci. 2011, 4, 1946-1971. [CrossRef]

6. Qadir, D.; Hilmi, M.; Lau Kok, K. Mixed matrix membranes for water purification applications. Sep. Purif. Rev. 2017, 46, 62-80. [CrossRef]

7. Kayvani Fard, A.; McKay, G.; Buekenhoudt, A.; Al Sulaiti, H.; Motmans, F.; Khraisheh, M.; Atieh, M. Inorganic membranes: Preparation and application for water treatment and desalination. Materials 2018, 11, 74. [CrossRef]

8. Maximous, N.; Nakhla, G.; Wong, K.; Wan, W. Optimization of Al2O3/PES membranes for wastewater filtration. Sep. Purif. Technol. 2010, 73, 294-301. [CrossRef]

9. Bottino, A.; Capannelli, G.; D'Asti, V.; Piaggio, P. Preparation and properties of novel organic-inorganic porous membranes. Sep. Purif. Technol. 2001, 22-23, 269-275. [CrossRef]

10. Pendergast, M.T.M.; Nygaard, J.M.; Ghosh, A.K.; Hoek, E.M.V. Using nanocomposite materials technology to understand and control reverse osmosis membrane compaction. Desalination 2010, 261, 255-263. [CrossRef]

11. Bae, T.H.; Tak, T.M. Effect of $\mathrm{TiO}_{2}$ nanoparticles on fouling mitigation of ultrafiltration membranes for activated sludge filtration. J. Membr. Sci. 2005, 249, 1-8. [CrossRef]

12. Agarwal, M.; Singh, K. Heavy metal removal from wastewater using various adsorbents: A review. J. Water Reuse Desalin. 2017, 7, 387-419.

13. Al-Khaldi, F.A.; Abusharkh, B.; Khaled, M.; Atieh, M.A.; Nasser, M.S.; Saleh, T.A.; Agarwal, S.; Tyagi, I.; Gupta, V.K. Adsorptive removal of Cadmium (II) ions from liquid phase using acid modified carbon-based adsorbents. J. Mol. Liq. 2015, 204, 255-263.

14. Ihsanullah; Al-Khaldi, F.A.; Abu-Sharkh, B.; Abulkibash, A.M.; Qureshi, M.I.; Laoui, T.; Atieh, M.A. Effect of acid modification on adsorption of hexavalent chromium $(\mathrm{Cr}(\mathrm{VI}))$ from aqueous solution by activated carbon and carbon nanotubes. Desalin. Water Treat. 2016, 57, 7232-7244. [CrossRef] 
15. Chen, C.; Hu, J.; Shao, D.; Li, J.; Wang, X. Adsorption behavior of multiwall carbon nanotube/iron oxide magnetic composites for Ni(II) and Sr(II). J. Hazard. Mater. 2009, 164, 923-928. [CrossRef]

16. Di, Z.C.; Li, Y.H.; Laun, Z.K.; Liang, J. Adsorption of chromium(VI) ions from water by carbon nanotubes. Adsorpt. Sci. Technol. 2004, 22, 467-474. [CrossRef]

17. Wang, S.G.; Gong, W.X.; Liu, X.W.; Yao, Y.W.; Gao, B.Y.; Yue, Q.Y. Removal of lead(II) from aqueous solution by adsorption onto manganese oxide-coated carbon nanotubes. Sep. Purif. Technol. 2007, 58, 17-23. [CrossRef]

18. Chen, C.; Wang, X. Adsorption of Ni (II) from aqueous solution using oxidized multiwall carbon nanotubes. Ind. Eng. Chem. Res. 2006, 45, 9144-9149. [CrossRef]

19. Chen, C.L.; Wang, X.K.; Nagatsu, M. Europium adsorption on multiwall carbon nanotube/iron oxide magnetic composite in the presence of polyacrylic acid. Environ. Sci. Technol. 2009, 43, 2362-2367. [CrossRef]

20. Lalia, B.S.; Ahmed, F.E.; Shah, T.; Hilal, N.; Hashaikeh, R. Electrically conductive membranes based on carbon nanostructures for self-cleaning of biofouling. Desalination 2015, 360, 8-12. [CrossRef]

21. Khan, A.A.; Khan, A.; Asiri, A.M. Nanocarbon and its composites for water purification. In Nanocarbon and Its Composites; Woodhead Publishing: Cambridge, UK, 2019; pp. 711-731.

22. Li, S.; Liao, G.; Liu, Z.; Pan, Y.; Wu, Q.; Weng, Y.; Zhang, X.; Yang, Z.; Tsuid, O.K.C. Enhanced water flux in vertically aligned carbon nanotube arrays and polyethersulfone composite membranes. J. Mater. Chem. A 2014, 2, 12171-12176. [CrossRef]

23. Lee, J. Carbon Nanotube-Based Membranes for Water Purification. In Nanoscale Materials in Water Purification; Elsevier: Amsterdam, The Netherlands, 2019; pp. 309-331.

24. Chaturvedi, S.; Dave, P.N. Water Purification Using Nanotechnology an Emerging Opportunities. Chem. Methodol. 2019, 3, 115-144.

25. Goh, P.S.; Ismail, A.F.; Ng, B.C. Carbon nanotubes for desalination: Performance evaluation and current hurdles. Desalination 2013, 308, 2-14. [CrossRef]

26. Hinds, B.J.; Chopra, N.; Andrews, R.; Gavalas, V.; Bachas, L.G. Aligned multiwalled carbon nanotube membranes. Science 2004, 303, 62-65. [CrossRef]

27. Wu, J.; Lu, Y.; Liu, Y.; Chen, J.; Han, B.; Bai, S.; Geng, D. Nitrogen-doped carbon nanotubes self-catalytically grown on desert sands towards water purification. J. Nanopart. Res. 2019, 21, 126. [CrossRef]

28. Chengwei, W.; Menke, L.; Shanlin, P.; Hulin, L. Well-aligned carbon nanotube array membrane synthesized in porous alumina template by chemical vapor deposition. Chin. Sci. Bull. 2000, 45, 1373-1376.

29. Srivastava, A.; Srivastava, O.N.; Talapatra, S.; Vajtai, R.; Ajayan, P.M. Carbon nanotube filters. Nat. Mater. 2004, 3, 610-614. [CrossRef]

30. Pandele, A.M.; Tuncel, C.; Voicu, S.I. Polymeric Composite Membranes Enabled by Carbon Nanotubes and Graphene for Water Purification. Mater. Sci. Technol. 2019, 1-18. [CrossRef]

31. Ihsanullah; Patel, F.; Khraisheh, M.; Atieh, M.A.; Laoui, T. Aluminum oxide impregnated carbon nanotube membranes for the removal of cadmium from aqueous solution. Materials 2017, 10, 1144.

32. Majeed, S.; Fierro, D.; Buhr, K.; Wind, J.; Du, B.; Fierro, A.B.D.; Abetz, V. Multi-walled carbon nanotubes (MWCNTs) mixed polyacrylonitrile (PAN) ultrafiltration membranes. J. Membr. Sci. 2012, 403-404, 101-109. [CrossRef]

33. Arockiasamy, D.L.; Alam, J.; Alhoshan, M. Carbon nanotubes-blended poly (phenylene sulfone) membranes for ultrafiltration applications. Appl. Water Sci. 2013, 3, 93-103. [CrossRef]

34. Choi, J.H.; Jegal, J.; Kim, W.N. Fabrication, and characterization of multi-walled carbon nanotubes/polymer blend membranes. J. Membr. Sci. 2006, 284, 406-415. [CrossRef]

35. Manafi, S.; Mohsen, E.; Fatemeh, S.B.; Iman, M. Structural properties and mechanical behavior of SWCNTs and MWCNTs reinforced $\mathrm{Al}_{2} \mathrm{O}_{3}$ fabricated by spark plasma sintering. Ceram. Int. 2019, 45, 15928-15933. [CrossRef]

36. Das, R.; Ali, M.E.; Hamid, S.B.A.; Ramakrishna, S.; Chowdhury, Z.Z. Carbon nanotube membranes for water purification: A bright future in water desalination. Desalination 2014, 336, 97-109. [CrossRef]

37. Smart, S.K.; Cassady, A.I.; Lu, G.Q.; Martin, D.J. The biocompatibility of carbon nanotubes. Carbon 2006, 44, 1034-1047. [CrossRef]

38. Wang, W.; Zhu, Y.; Liao, S.; Li, J. Carbon nanotubes reinforced composites for biomedical applications. BioMed Res. Int. 2014, 2014, 518609. [CrossRef]

39. Barma, S.; Bishnupada, M. Effects of sintering temperature and initial compaction load on alpha-alumina membrane support quality. Ceram. Int. 2014, 40, 11299-11309. [CrossRef] 
40. Patel, F.; Baig, M.A.; Laoui, T. Processing of porous alumina substrate for the multilayered ceramic filter. Desalin. Water Treat. 2011, 35, 33-38. [CrossRef]

41. Ghaderi, M.J.; Mahdi, S.A.; Ghodratollah, R. Synthesis of alumina porous supports via different compaction routes: Vibration and pressing. J. Chem. Technol. Metall. 2013, 48, 289-295.

42. Qin, W.; Peng, C.; Lv, M.; Wu, J. Preparation and properties of high-purity porous alumina support at the low sintering temperature. Ceram. Int. 2014, 40, 13741-13746. [CrossRef]

43. Hai, C.; Takashi, S.; Masayoshi, F. Fabrication of conductive porous alumina (CPA) structurally modified with carbon nanotubes (CNT). Adv. Powder Technol. 2013, 24, 824-828. [CrossRef]

44. Parham, H.; Andrew, K.; Yanqiu, Z. Preparation of porous alumina-carbon nanotube composites via direct growth of carbon nanotubes. Compos. Sci. Technol. 2011, 71, 1739-1745. [CrossRef]

45. Saheb, N.; Umer, H.; Syed, F.H. Recent Advances and Future Prospects in Spark Plasma Sintered Alumina Hybrid Nanocomposites. Nanomaterials 2019, 9, 1607. [CrossRef]

46. Momohjimoh, I.; Mohamed, A.H.; Nasser, A.-A. Recent advances in the processing and properties of alumina-CNT/SiC nanocomposites. Nanomaterials 2019, 9, 86. [CrossRef]

47. Jayaseelan, D.D.; Kondo, N.; Brito, M.E.; Ohji, T. High-Strength Porous Alumina Ceramics by the Pulse Electric Current Sintering Technique. J. Am. Ceram. Soci. 2002, 85, 267-269. [CrossRef]

48. Oh, S.T.; Tajima, K.; Ando, M.; Ohji, T. Strengthening of Porous Alumina by Pulse Electric Current Sintering and Nanocomposite Processing. J. Am. Ceram. Soc. 2000, 83, 1314-1316. [CrossRef]

49. Green, D.J.; Nader, C.; Brezny, R. The Elastic Behavior of Partially-Sintered Alumina. In Ceramic Transactions, Vol. 7, Sintering of Advanced Ceramics; Handwerker, C.A., Blendell, J.E., Kaysser, W.A., Eds.; American Ceramic Society: Westerville, OH, USA, 1990; pp. 345-356.

50. Lam, D.C.C.; Lange, F.F.; Evans, A.G. Mechanical Properties of Partially Dense Alumina Produced from Powder Compacts. J. Am. Ceram. Soc. 1994, 77, 2113-2117. [CrossRef]

51. Nanjangud, S.C.; Brezny, R.; Green, D.J. Strength and Young's Modulus The behavior of a Partially Sintered Porous Alumina. J. Am. Ceram. Soc. 1995, 78, 266-268. [CrossRef]

52. Kawai, C.; Yamakawa, A. Effect of Porosity and Microstructure on the Strength of $\mathrm{Si}_{3} \mathrm{~N}_{4}$ : Designed Microstructure for High Strength, High Thermal Shock Resistance, and Facile Machining. J. Am. Ceram. Soc. 1997, 80, 2705-2708. [CrossRef]

53. Li, G.; Jiang, Z.; Zhang, L. Strengthening of Porous $\mathrm{Al}_{2} \mathrm{O}_{3}$ Ceramics through Nanoparticle Addition. Nanostruct. Mater. 1997, 80, 749-754. [CrossRef]

54. David, C.C. Mechanical Testing Methodology for Ceramic Design and Reliability, 1st ed.; CRC Press: Boca Raton, FL, USA, 1998.

55. Shahzad, H.K.; Hussein, M.A.; Patel, F.; Al-Aqeeli, N.; Atieh, M.A.; Laoui, T. Synthesis and characterization of alumina-CNT membrane for cadmium removal from aqueous solution. Ceram. Int. 2018, 44, 17189-17198. [CrossRef]

56. Gupta, V.K.; Shilpi, A.; Tawfik, A.S. Synthesis and characterization of alumina-coated carbon nanotubes and their application for lead removal. J. Hazard. Mater. 2011, 185, 17-23. [CrossRef]

57. Niihara, K. New Design Concept of Structural Ceramics-Nanocomposites. J. Ceram. Soc. Jpn. 1991, 99, 974-982. [CrossRef]

58. German, R.M. Sintering Theory and Practice; John Wiley \& Sons: New York, NY, USA, 1996.

59. Falamaki, C.; Afarani, M.S. Aghaie Initial sintering stage pore growth mechanism applied to the manufacture of ceramic membrane supports. J. Eur. Ceram. Soc. 2004, 24, 2285-2292. [CrossRef]

60. Ibrahim, S.H.; Skibinski, J.; Oliver, G.J.; Wejrzanowski, T. Microstructure effect on the permeability of the tape-cast open-porous materials. Mater. Des. 2019, 167, 107639. [CrossRef]

61. Spriggs, R.M.; Vasilos, T. Effect of grain size on transverse bend strength of alumina and magnesia. J. Am. Ceram. Soc. 1963, 46, 224-228. [CrossRef]

62. Le, N.L.; Suzana, P.N. Materials and membrane technologies for water and energy sustainability. Sustain. Mater. Technol. 2016, 7, 1-28. [CrossRef]

63. Ananthakumar, S.; Warrier, K.G.K. Extrusion characteristics of alumina-aluminum titanate composite using boehmite as a reactive binder. J. Eur. Ceram. Soc. 2001, 21, 71-78. [CrossRef]

64. Huang, J.H.; Zeng, G.M.; Zhou, C.F.; Li, X.; Shi, L.J.; He, S.B. Adsorption of surfactant micelles and Cd 2+/Zn 2+ in micellar-enhanced ultrafiltration. J. Hazard. Mater. 2010, 183, 287-293. [CrossRef] 
65. Landaburu-Aguirre, J.; Pongrácz, E.; Perämäk, P.; Keiski, R.L. Micellarenhanced ultrafiltration for the removal of cadmium and zinc: Use of response surface methodology to improve understanding of process performance and optimisation. J. Hazard. Mater. 2010, 180, 524-534. [CrossRef]

66. Rao, G.P.; Lu, C.; Su, F. Sorption of divalent metal ions from aqueous solution by carbon nanotubes: A review. Sep. Purif. Technol. 2007, 58, 224-231. [CrossRef]

67. Cervera, M.L.; Arnal, M.C.; de la Guardia, M. Removal of heavy metals by using adsorption on alumina or chitosan. Anal. Bioanal. Chem. 2003, 375, 820-825.

68. Kuo, C.Y.; Lin, H.Y. Adsorption of aqueous cadmium (II) onto modified multi-walled carbon nanotubes following microwave/chemical treatment. Desalination 2009, 249, 792-796. [CrossRef]

69. Fu, F.; Qi, W. Removal of heavy metal ions from wastewaters: A review. J. Environ. Manag. 2011, 92, 407-418. [CrossRef]

(C) 2020 by the authors. Licensee MDPI, Basel, Switzerland. This article is an open access article distributed under the terms and conditions of the Creative Commons Attribution (CC BY) license (http://creativecommons.org/licenses/by/4.0/). 